\title{
Hybrid-layered manufacturing using tungsten inert gas cladding
}

\author{
Sajan Kapil ${ }^{1} \cdot$ Fisseha Legesse $^{1} \cdot$ Pravin Kulkarni $^{1} \cdot{\text { Prathamesh } \text { Joshi }^{1}}$. \\ Ankit Desai $^{1}$ - K. P. Karunakaran ${ }^{1}$
}

Received: 11 February 2016/Accepted: 17 February 2016/Published online: 22 March 2016

(c) Springer International Publishing Switzerland 2016

\begin{abstract}
Among the different additive manufacturing (AM) processes, hybrid-layered manufacturing (HLM) is the AM process of metals which combines the best features of additive and subtractive manufacturing techniques. In HLM process, the metal is deposited by a cladding process and after the deposition of near-net shape, a machining operation is used for achieving dimensional accuracy. In this work, TIG cladding-based HLM process has been studied and stabilized by retrofitting a TIG cladding unit on an existing CNC machine. The behavior of TIG-HLM process has been studied for a mild steel cladding wire ER70S-6 of $1.2 \mathrm{~mm}$ diameter by performing the three types of experiments: single-bead, multi-bead and multilayer experiments. The single-bead experiments are performed along with Taguchi and ANOVA to find out the contribution of process parameters such as cladding current, torch speed, wire feed rate and standoff distance on the bead width, height and penetration. The multi-bead experiments are performed to find out the optimal height of
\end{abstract}

Pravin Kulkarni

kulkarnipravin.89@gmail.com

Sajan Kapil

kapil.sajan17@gmail.com

Fisseha Legesse

fissehal@gmail.com

Prathamesh Joshi

prathamesh1729@gmail.com

Ankit Desai

ankitdesai08@gmail.com

K. P. Karunakaran

karuna@iitb.ac.in

1 Mechanical Engineering Department, Indian Institute of Technology Bombay, Mumbai 400076, India a layer where bead width is the input parameter. The multilayer experiments are required for the characterization of the process and consist of hardness test by nano-indentation testing, microstructure analysis by electron backscattered diffraction, and interlayer fusion test by X-ray analysis. A case study has been done by manufacturing a cylindrical object of $50 \mathrm{~mm}$ height using this process.

Keywords Additive manufacturing (AM) - Hybridlayered manufacturing (HLM) · Tungsten inert gas (TIG) · Taguchi - ANOVA - Electron backscattered diffraction (EBSD)

\section{Introduction}

Direct metal deposition (DMD) developed at Southern Methodist University, USA is a 3D Welding process which uses tungsten inert gas (TIG) cladding process for deposition [1-4]. Although they used an MIG cladding in the beginning, they subsequently shifted to a TIG cladding as they found it to be a much more controllable process for deposition with fewer problems of sputtering, intensive heating, smoke, etc. One of the difficulties with TIG is the need for orienting the automatic wire feeder nozzle to match with the torch direction, which adds a rotary axis in addition to $X$ and $Y$ during the deposition. A novel freeform fabrication method named 3D microwelding (3DMW) has been developed using an idea to combine free-form fabrication method with TIG by researchers of Osaka University, Japan [5, 6]. When pulsed micro-arcs are emitted, the tip of a thin metal wire with a diameter of $0.1-0.3 \mathrm{~mm}$ is fused and a micrometal bead is formed instantaneously. The fused bead is welded to a metal substrate or previously formed layers. By continuing this 
process and building up hot beads layer by layer under the control of CAD/CAM system, 3D metal objects can be produced. This process can be applied not only to titanium, but also to other refractory metals such as tantalum, tungsten due to the high-density energy beam of the micro arc. When thin wires of two different metals such as Ti and $\mathrm{Ni}$, or $\mathrm{Ni}$ and $\mathrm{Al}$ are fed alternately from the opposed spools, it is possible to build complex 3D structures and components composed of their alloys or inter-metallic compounds. Shape deposition manufacturing (SDM) is another arc-based deposition process which makes use of deposition and milling [7-9]. It uses a pair of materials, one for model and the other for support. Copper is used as the support material for steel models. Unlike the uniform slicing used in 3D welding, it uses very thick segments. These segments are obtained by splitting the object wherever its normal just becomes horizontal. In any slice, all regions of the slice where the normal points downward, support is required. This near-net shape is then finished for the deposition of the model material. Thus, each slice is built by deposition and machining of support and model materials alternately until the entire slab of the slice is complete. Owing to its five-axis kinematics and path planning involved, SDM is not a fully automatic process. Wire + Arc Additive Manufacturing (WAAM), at Cranfield University, UK, uses TIG and plasma welding combined with a wire feeding system $[10,11]$. For Ti-6Al-4V they can produce a wall of width $17.5 \mathrm{~mm}$ and claim that the deposition rate can be achieved up to $1.8 \mathrm{~kg}$ per hour. Using this process $\mathrm{Ti}$ spar, steel turbine blade, etc., are manufactured. Plasma arc process is an extension of the TIG cladding process. Hybrid plasma deposition and milling (HPDM) is the process which uses plasma as a power source. This process is developed at Wuhan University, China [12, 13]. It employs the combination of plasma deposition as an additive and milling as a subtractive process. The machine has two working procedures: deposition by plasma and surface finishing by NC milling head. In the HPDM process, plasma deposition is used to deposit single beads side by side. When a layer is deposited, its top surface is machined using planar milling to obtain a smooth surface. After all the layers are deposited, the near-net shape is finish machined on the same platform. In next section, the hybrid-layered manufacturing (HLM) process has been described in detail.

\subsection{Hybrid-layered manufacturing}

Hybrid-layered manufacturing (HLM) process combines the better features of additive and subtractive techniques. In this process, first the near-net shape of the object is manufactured by layered deposition (Addition) using metal inert gas (MIG) cladding or tungsten inert gas (TIG) cladding process. The near-net shape is then finish machined using CNC machining (Subtraction).

HLM was started in IIT Bombay as an RM technology that uses a pulsed synergic MIG deposition unit. The HLM systems allow the production of large and low-volume workpiece with high or optimal deposition rates. Deposition rates that can be achieved with MIG-HLM vary from a few grams (50-100) to Kgs (2-3) per hour. Figure 1 shows the components of the HLM process. Total automation in arc HLM is realized through a synergic integration of the cladding equipment with the $\mathrm{CNC}$ machine. This retro fitment is done in such a manner that weld deposition is an additional feature to an existing three- or five-axis CNC machine without disturbing its other capabilities [15]. Similar to MIG-HLM, TIG-HLM also works on the same principle of addition and subtraction, the only difference is, as the name suggests, in the cladding source. The experimental setup of TIG-HLM has been described in next section.

\section{Experimental setup}

Synergic integration of cladding unit with the CNC machine irrespective of its make is a key aspect in HLM. The primary challenge in implementing an HLM system is to add the feature of cladding without hampering the original capabilities of the CNC machine. During the fabrication of the near-net shape, cladding and surface milling happen alternately. HLM process is proposed in such way that anyone can retrofit this setup on an existing CNC machine. Though the CNC machine used in experiments has an automatic tool changer (ATC) arrangement, the

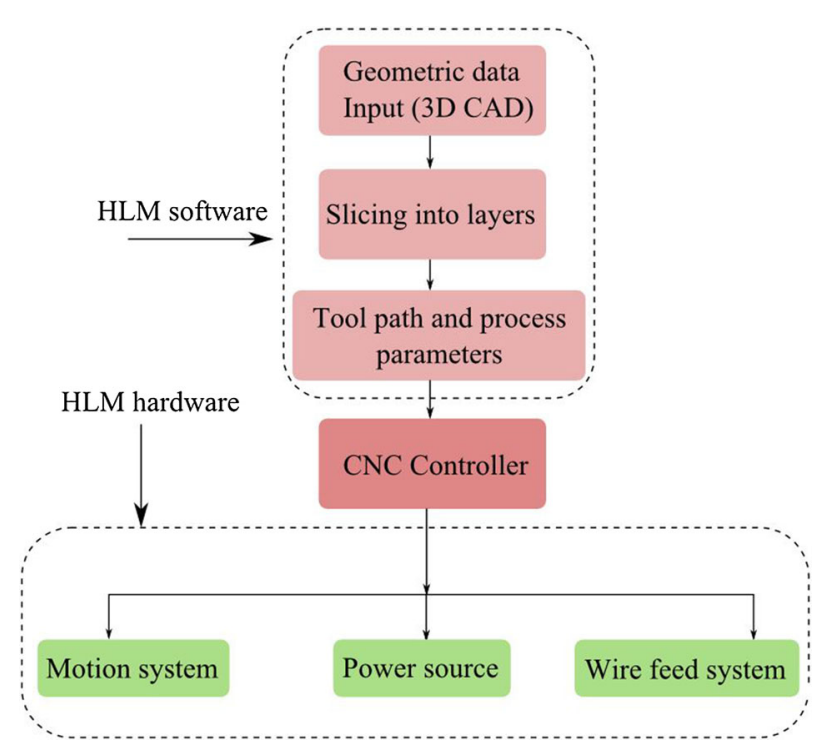

Fig. 1 HLM system components 


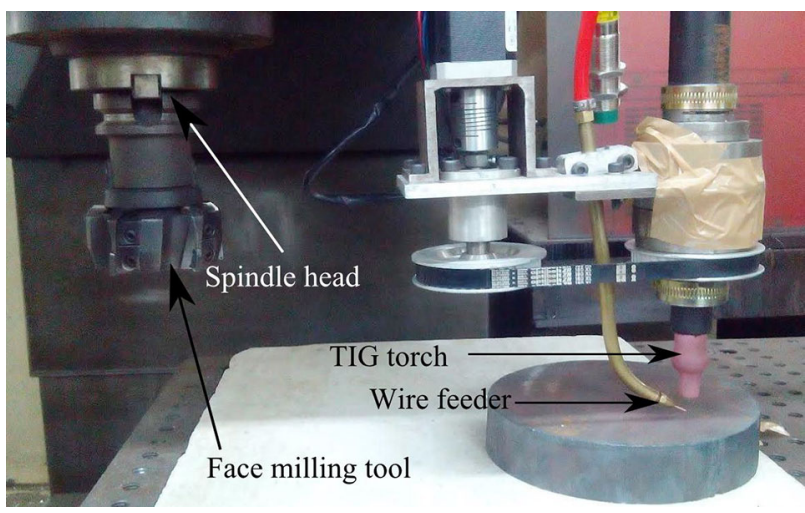

Fig. 2 TIG gun mounted on CNC machine

torch cannot be accommodated in one of the pockets as it has a long hose. This problem is overcome by mounting the torch on a side of the spindle head as shown in Fig. 2.

In case of TIG cladding process on a three-axis machine, after material deposition, it is required to do face milling. But the cladding torch datum is lower than the milling cutter datum, so it is not possible to do milling without removal or retraction of torch. But to save this manual effort and to avoid misalignment of gun (which can be caused during removal) a retractable design is introduced. It is a customized pneumatic arrangement for automatic retraction of cladding torch. This pneumatic arrangement will retract gun to a desired position at a height well above the milling datum during milling; and after milling it will again be extended to the initial position for deposition, see Fig. 3.

In the CNC machine, there are additional relays which can be assigned to programmatically switch the TIG machine $\mathrm{ON}$ and OFF. But in case of this experiment there is no requirement of any additional relay. In this case, nonessential relay during the HLM process is used and can be addressed by a pair of $\mathrm{M}$ codes. The coolant ON/OFF operation is not required during deposition process; therefore, this same relay is used for HLM implementation. Thus, M08/M09 will control deposition in HLM mode and coolant flow in regular CNC mode. Figure $4 \mathrm{a}$ shows the control circuit of deposition unit and CNC machine. One wire from the power source is kept connected to the feeder and the other end is connected to the CNC relay which makes or breaks the power to the wire feeder. In TIG deposition unit, there are two modes: One is called twostep mode and the other is four-step mode shown in Fig. 4b. In the two-step mode, a continuous high trigger has to be given during cladding. When the trigger is released, the cladding stops. On the other hand, in the fourstep mode, cladding starts the moment the trigger is pressed; it continues even after the trigger is released. In this mode, the same trigger should be pressed once more to stop

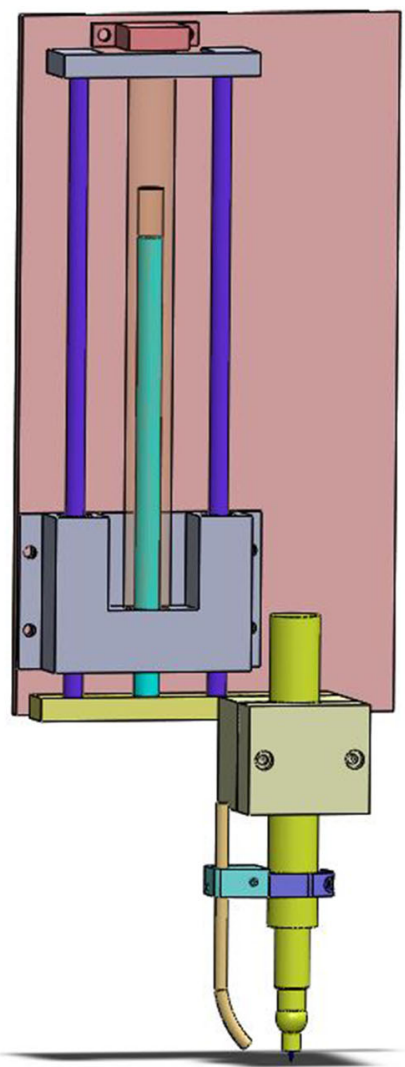

(a)

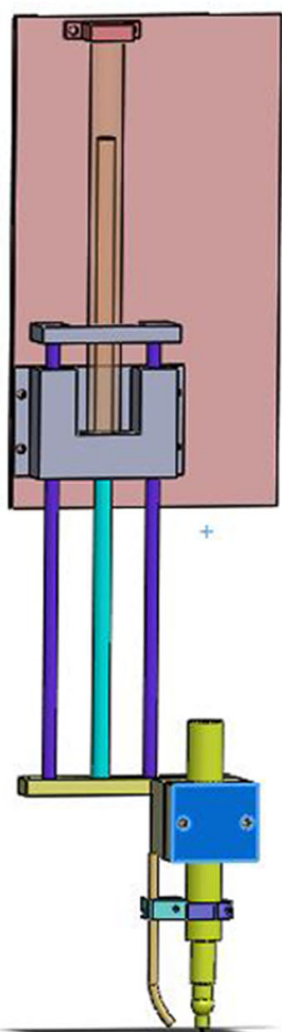

(b)
Fig. 3 CAD model of pneumatic arrangement in a retracted, b extended positions

the cladding. Figure 5 shows the NC code used for twostep mode and four-step mode. In our experiments, we use the four-step mode always.

\section{Process parameters}

The process parameters of HLM have to be optimally chosen so as to minimize material wastage and heat input in addition to ensuring that the heat distribution happens over a wider area. This requires a better understanding of the influential process parameters and their inter-dependencies. Three types of flows occur during deposition. These are current flow, heat flow, and mass transfer. The TIG cladding parameters can be categorized as listed in Table 1.

The TIG cladding parameters influencing the near-net shape of the component are further categorized in Table 2. Depending on the experiment mode which they influence, the parameters are further divided into three categories (single-bead experiments, multi-bead experiments and multi-layer experiments) based on the hierarchy explained in Fig. 6. 
Fig. 4 a Control circuit of deposition unit and $\mathrm{CNC}$ machine. b Control panel of deposition unit

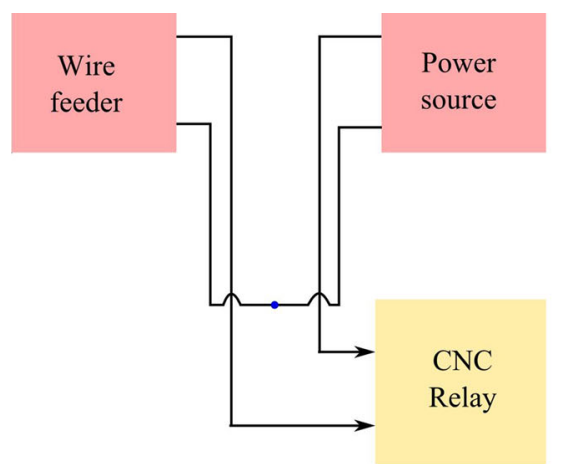

(a)

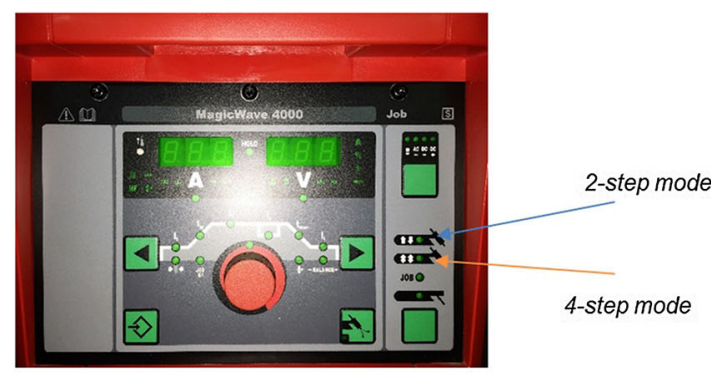

(b)
Fig. 5 NC code for two- and four-step mode a two-step mode, $\mathbf{b}$ four-step mode

\section{M590 Welding start (connections in contact) $X-35.481 F Q 2$ \\ $\mathrm{X}-43.615 \mathrm{C}-2.941$ \\ $X-44.826$ C-9.271 \\ X-44.995 Y-44.993 C-32.746 \\ $X-44.992$ Y-44.824 C-69.552 \\ $X-44.991$ Y-44.653 C-85.326 \\ Y-22.673 C-90.0 \\ M591 Welding stop (connections not in contact)}

M590 Welding start (connections in contact)

M591 (connections not in contact)

$\mathrm{X}-35.481 \mathrm{FQ2}$

$X-43.615$ C-2.941

$X-44.826$ C-9.271

$X-44.995$ Y-44.993 C-32.746

$X-44.992$ Y-44.824 C-69.552

$X-44.991 Y-44.653$ C-85.326

Y-22.673 C-90.0

M590 Welding stop (connections in contact)

M591 (connections not in contact)

(a)

(b)

Table 1 Various parameters of TIG cladding

\begin{tabular}{ll}
\hline Category & Parameters \\
\hline Power & Arc voltage \\
& Starting, main, reduced and final current \\
Filler & Wire type (material composition, coating, coring, etc.) \\
& Wire diameter \\
& Wire feed rate \\
Gas & Gas proportion \\
& Gas pressure \\
& Gas flow rate \\
& Gas pre-flow period \\
& Gas post-flow period \\
Layer thickness & Bead width \\
Deposition & Bead height or reinforcement height \\
& Distance between nozzle and base plate \\
& Distance between electrode contact tip and base plate \\
& Torch speed \\
Type of area-filling & Step over increment \\
& Machining allowance
\end{tabular}

\subsection{Single-bead experiments}

To understand the relationship between the input and output parameters of single-bead formation, experiments were carried out for different values of input parameters. Optimization of process parameters is the key step in the Taguchi method to achieving high-quality bead [14]. This is because optimization of process parameters can improve quality characteristics and the optimal process parameters obtained from the Taguchi method are insensitive to the variation of environmental conditions and other noise factors. There are three categories of the quality characteristic in the analysis of the $S / N$ ratio, i.e., the lower-thebetter, higher-the-better and the nominal-the-better. The $S /$ $N$ ratio for each level of process parameters is computed based on the $S / N$ analysis. Regardless of the category of the quality characteristic, a larger $S / N$ ratio corresponds to a better quality characteristic. Therefore, the optimal level of the process parameters is the level with the highest $S /$ $N$ ratio. Furthermore, a statistical analysis of variance (ANOVA) is performed to see which process parameters are statistically significant. The optimal combination of the process parameters can then be predicted. Finally, a con- 
Table 2 Parameters influencing the near-net shape

\begin{tabular}{lll}
\hline & Input & Output \\
\hline Single-bead experiments & Torch speed $(\mathrm{mm} / \mathrm{min})$ & Height of bead $(\mathrm{mm})$ \\
& Wire feed rate $(\mathrm{mm} / \mathrm{min})$ & Bead penetration $(\mathrm{mm})$ \\
& Current $($ Amp) & Width of bead $(\mathrm{mm})$ \\
& Standoff distance $(\mathrm{mm})$ & \\
Multi-bead experiments & Pitch of bead $(\mathrm{mm})$ & Height of layer \\
Multi-layer experiments & Layer thickness & Hardness test \\
& & Microstructure analysis \\
& & Interlayer fusion quality (X-ray)
\end{tabular}
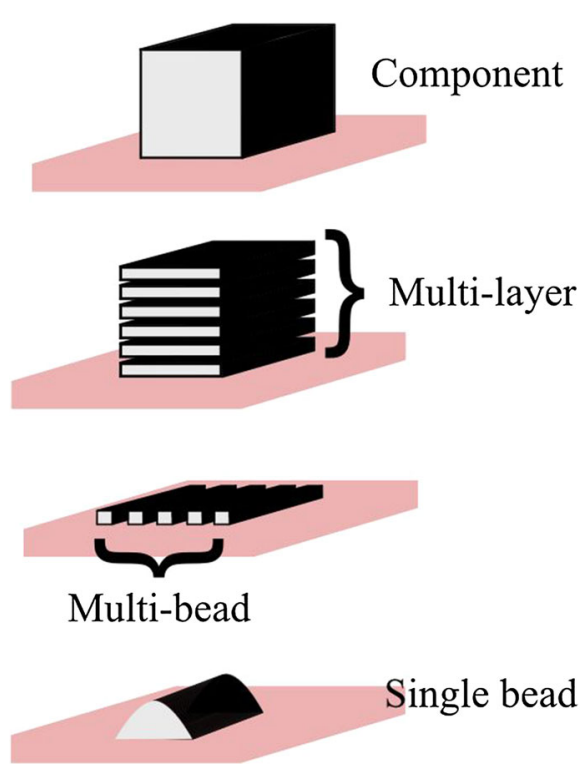

Fig. 6 Hierarchy in the additive manufacturing of the components in HLM

firmation experiment is conducted to verify the optimal process parameter. To carry out Taguchi and ANOVA analysis, the range of parameters has to be decided first. In the present study, four levels of process parameters, i.e., torch speed, current, wire feed and standoff distance, are considered. The values of the cladding process parameter for mild steel (ER70S-6) wire of $1.2 \mathrm{~mm}$ diameter at the different levels are listed in Table 3.

The interaction effect between the input cladding parameters is neglected. In this study, an L16 orthogonal array which has $15^{\circ}$ of freedom is used. Sixteen experiments are required to study the entire cladding parameter space when the L16 orthogonal array is used. The experimental layout for the cladding process parameters using the L16 orthogonal array and the experimental results obtained are shown in Table 4. To measure the values of width, height and penetration a stereo microscope has been used after sample preparation by polishing with $\mathrm{SiC}$ papers of 150-500 grit sizes and etching with methanol and nitric acid (98:2). The example of one image obtained from the results of the stereo microscope has been shown in the Fig. 7.

The overall loss function is further transformed into the $S / N$ ratio. In the Taguchi method, the $S / N$ ratio is used to determine the deviation of the quality characteristic from the desired. The $S / N$ ratio $\eta$ is defined as

$\eta=-10 \log \left(\frac{1}{n} \sum_{i=1}^{n} \frac{1}{y_{i}^{2}}\right)$

where $n$ is the number of observations on the particular experiment ( $n=1$ in this case) and $y_{i}$ is the respective measured output value given in Table 4 . The $S / N$ ratio corresponding to the overall loss function is shown in Table 5. The effect of each cladding process parameter on the $S / N$ ratio at different levels can be separated out because the experimental design is orthogonal.

The mean of the $S / N$ ratio for each level of the cladding process parameters is summarized and shown in Table 6 . Figure 8 gives the plot of the factors' effects on the width, height, and penetration. The conditions for maximum output are:

For width is W1T1C4S3, Fig. 8a.

For height is W3T3C1S2, Fig. 8b.

For penetration is W2T3C2S4, Fig. 8c.
Table 3 Process parameter and their levels

\begin{tabular}{lllrrrr}
\hline Notation & Process parameter & Unit & Level 1 & Level 2 & Level 3 & Level 4 \\
\hline $\mathrm{W}$ & Wire feed & $\mathrm{mm} / \mathrm{min}$ & 1500 & 1750 & 2000 & 2250 \\
$\mathrm{~T}$ & Torch speed & $\mathrm{mm} / \mathrm{min}$ & 200 & 250 & 300 & 350 \\
$\mathrm{C}$ & Current & Amps & 180 & 190 & 200 & 210 \\
$\mathrm{~S}$ & Standoff distance & $\mathrm{mm}$ & 5 & 6 & 7 & 8 \\
\hline
\end{tabular}


Table 4 Experimental results for single bead

\begin{tabular}{|c|c|c|c|c|c|c|c|}
\hline Exp. no & Level of W & Level of $\mathrm{T}$ & Level of C & Level of $\mathrm{S}$ & Width (mm) & Height (mm) & Penetration $(\mathrm{mm})$ \\
\hline 1 & 1 & 1 & 1 & 1 & 8.80 & 1.6 & 0.89 \\
\hline 2 & 1 & 2 & 2 & 2 & 7.89 & 1.71 & 1.43 \\
\hline 3 & 1 & 3 & 3 & 3 & 8.76 & 1.51 & 0.91 \\
\hline 4 & 1 & 4 & 4 & 4 & 9.30 & 1.60 & 0.96 \\
\hline 5 & 2 & 1 & 2 & 3 & 10.08 & 2.13 & 1.29 \\
\hline 6 & 2 & 2 & 1 & 4 & 8.21 & 1.92 & 1.01 \\
\hline 7 & 2 & 3 & 4 & 1 & 9.01 & 1.58 & 0.84 \\
\hline 8 & 2 & 4 & 3 & 2 & 7.32 & 1.82 & 1.25 \\
\hline 9 & 3 & 1 & 3 & 4 & 10.12 & 2.19 & 1.24 \\
\hline 10 & 3 & 2 & 4 & 3 & 10.38 & 2.09 & 1.06 \\
\hline 11 & 3 & 3 & 1 & 2 & 5.00 & 2.77 & 1.09 \\
\hline 12 & 3 & 4 & 2 & 1 & 6.93 & 1.85 & 0.59 \\
\hline 13 & 4 & 1 & 4 & 2 & 10.19 & 2.51 & 0.62 \\
\hline 14 & 4 & 2 & 3 & 1 & 9.23 & 1.36 & 0.67 \\
\hline 15 & 4 & 3 & 2 & 4 & 6.12 & 2.81 & 1.28 \\
\hline 16 & 4 & 4 & 1 & 3 & 7.22 & 2.35 & 0.65 \\
\hline
\end{tabular}

Fig. 7 a Deposited single beads for designed orthogonal array L16. b Nomenclature of bead output parameters. c Example of an image obtained from the stereo microscope of the singlebead cut section

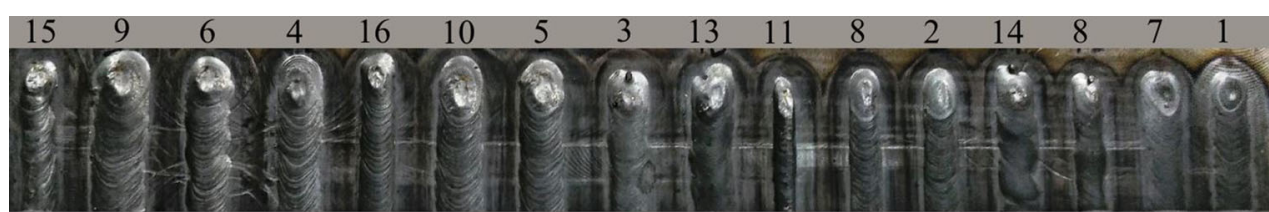

(a)

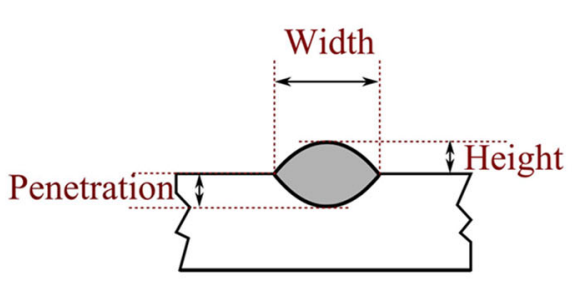

(b)

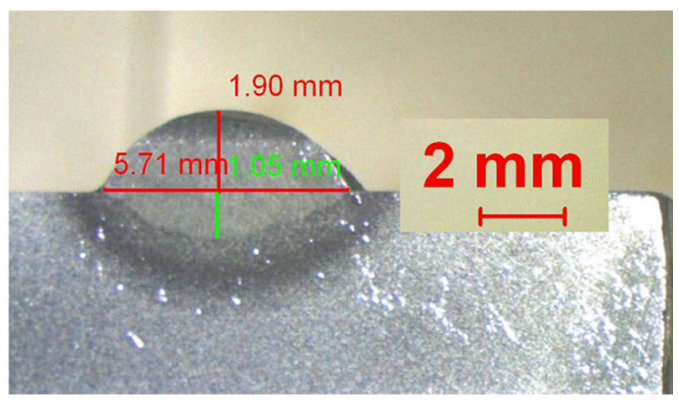

(c)

\section{Analysis of variance (ANOVA)}

The purpose of the analysis of variance (ANOVA) is to investigate which parameters significantly affect the performance characteristic. Detailed descriptions of results obtained by analysis of variance are given in Table 7. DOF stands for degree of freedom, SS for sum of squares, MS for mean square and $F$ is $F$ ratio. The degree of freedom can be defined as

$\mathrm{DOF}=n_{l}-1$

where $n_{l}$ is the number of levels for the parameter. The sum of squares can be calculated using following equation.
$\mathrm{SS}=\frac{1}{n_{l}} \sum_{i=1}^{n_{l}}\left(X_{i}-\bar{X}\right)^{2}$

where $X_{i}$ is the mean $S / N$ ratio for $i$ th level and $\bar{X}$ is the average of $S / N$ ratio for the particular output (calculated from Table 5). The mean square can be computed as the ratio of corresponding SS and DOF.

$\mathrm{MS}=\frac{\mathrm{SS}}{\mathrm{DOF}}$

Similarly, the $F$ ratio can be obtained as:

$F=\frac{\mathrm{MS}}{\mathrm{MSE}}$ 
Table $5 S / N$ ratio for bead characteristics

\begin{tabular}{lcllllr}
\hline Exp. no & Width $(\mathrm{mm})$ & $S / N$ ratio & Height $(\mathrm{mm})$ & $S / N$ ratio & Penetration & $S / N$ ratio \\
\hline 1 & 8.8 & 18.88 & 1.6 & 4.08 & 0.89 & -1.01 \\
2 & 7.89 & 17.94 & 1.71 & 4.68 & 1.42 & 3.10 \\
3 & 8.76 & 18.85 & 1.51 & 3.60 & 0.91 & -0.82 \\
4 & 9.30 & 19.37 & 1.60 & 4.09 & 0.95 & -0.39 \\
5 & 10.08 & 20.07 & 2.13 & 6.57 & 1.29 & 2.21 \\
6 & 8.21 & 18.29 & 1.91 & 5.66 & 1.01 & 0.07 \\
7 & 9.01 & 19.09 & 1.58 & 3.97 & 0.84 & -1.51 \\
8 & 7.32 & 17.29 & 1.82 & 5.20 & 1.25 & 1.92 \\
9 & 10.12 & 20.10 & 2.18 & 6.80 & 1.24 & 1.88 \\
10 & 10.38 & 20.32 & 2.08 & 6.39 & 1.06 & 0.54 \\
11 & 5.00 & 13.99 & 2.76 & 8.84 & 1.09 & 0.74 \\
12 & 6.93 & 16.81 & 1.85 & 5.34 & 0.58 & -4.65 \\
13 & 10.19 & 20.16 & 2.51 & 8.00 & 0.62 & -4.12 \\
14 & 9.23 & 19.30 & 1.36 & 2.67 & 0.67 & -3.41 \\
15 & 6.12 & 15.73 & 2.81 & 8.98 & 1.28 & 2.17 \\
16 & 7.22 & 17.18 & 2.34 & 7.41 & 0.65 & -3.75 \\
\hline
\end{tabular}

Table 6 Mean $S / N$ ratio for bead characteristics

\begin{tabular}{|c|c|c|c|c|c|c|c|c|c|c|c|c|}
\hline & \multicolumn{12}{|c|}{ Mean $S / N$ ratio } \\
\hline & \multicolumn{4}{|l|}{ Width } & \multicolumn{4}{|l|}{ Height } & \multicolumn{4}{|c|}{ Penetration } \\
\hline & Level 1 & Level 2 & Level 3 & Level 4 & Level 1 & Level 2 & Level 3 & Level 4 & Level 1 & Level 2 & Level 3 & Level 4 \\
\hline Wire feed & 18.76 & 18.68 & 17.81 & 18.09 & 4.11 & 5.35 & 6.84 & 6.76 & 0.21 & 0.67 & -0.37 & -2.28 \\
\hline Torch speed & 19.81 & 18.96 & 16.92 & 17.66 & 4.85 & 4.85 & 6.35 & 5.51 & 0.67 & 0.07 & 0.70 & 0.41 \\
\hline Current & 17.09 & 17.64 & 18.89 & 19.73 & 6.49 & 6.39 & 4.57 & 5.61 & -0.36 & 0.14 & -0.10 & -0.45 \\
\hline Standoff distance & 18.52 & 17.35 & 19.10 & 18.37 & 4.01 & 6.68 & 5.99 & 6.38 & 6.66 & -2.27 & -1.71 & -1.37 \\
\hline
\end{tabular}

where MSE is the mean square value of error. The percentage contribution of each parameter is

$\%$ contribution $=\frac{F}{\sum F} \times 100$

Further the results shown in Table 7 are summarized for the percentage contribution of each factor on performance characteristics in Fig. 9. One can conclude from this analysis that the percentage contribution of torch speed, wire feed and stand off distance is highest on bead width, height and penetration, respectively.

\subsection{Multi-bead experiments}

In HLM, a layer is built by depositing a series of overlapping beads followed by face milling to remove the scallops. Layer thickness is the thickness of the deposited layer after face milling. In multi-bead experiments the stepover or the pitch between two beads plays a very important role in converting the beads into layer. When the pitch is less than the bead width, two beads overlap and thus by several such overlapping beads one layer is formed. The thickness of the layer also depends on the stepover increment of the consecutive beads. From Fig. 10, it is clearly seen that the stepover increment decides the initial thickness of the layer. To minimize material wastage in face milling, the optimal stepover $(P)$ can be computed from the width $(w)$ by the Eq. 7, [16].

$P=\frac{2}{3} w$

To predict the layer thickness the bead height is an important parameter and also the width of the deposited bead is an input for estimating the pitch between two consecutive beads. Hence, it is desirable to record the width and height of the beads for different value of process parameters. Figure 11 shows the nozzle and wire position of automatic wire feeder. This position was selected on the basis of continuous arc glow, complete wire melting and continuity of the bead without any waviness. The torch speed and standoff distance are fixed to $200 \mathrm{~mm} / \mathrm{min}$ and $7 \mathrm{~mm}$, respectively, while the current 
Fig. 8 Plot of factor effects on a width, b height, $\mathbf{c}$ penetration

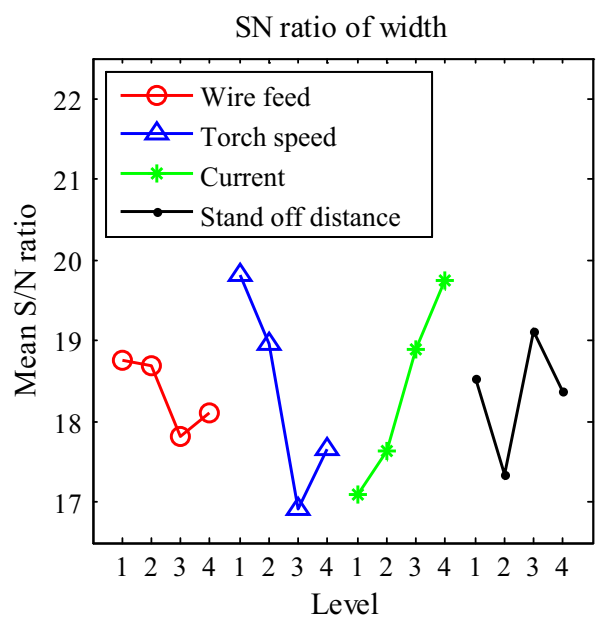

(a)

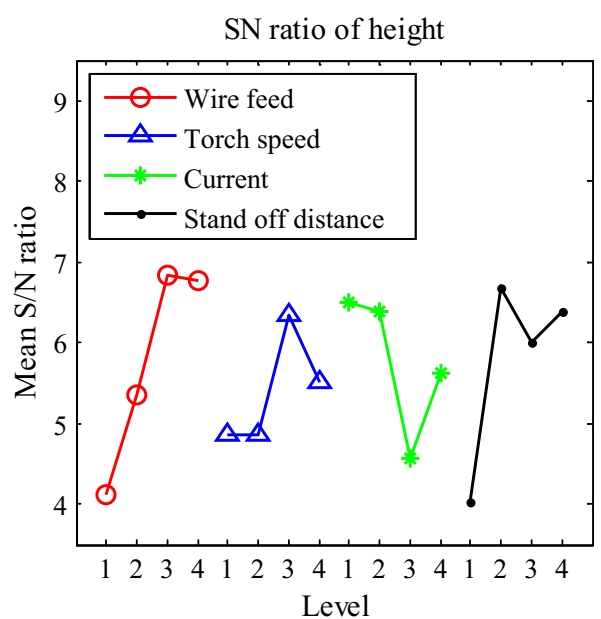

(b)

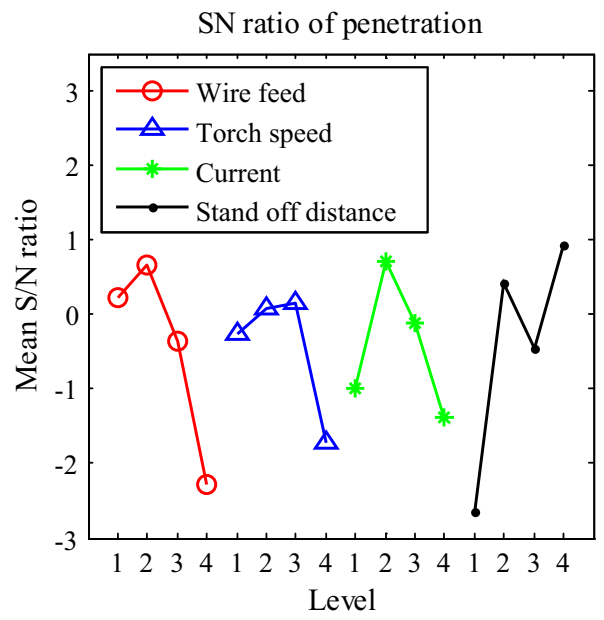

(c)

and wire feed rate are varied over a wide range. Figure 12 shows results of penetration, width and height of single-bead deposition at different current ranges for different wire feed rates. It can be easily observed from Fig. 12 that with increasing current, the penetration and width is increasing and height of bead is decreasing. Therefore, as per the requirement of output parameters, the appropriate combination of wire feed and current can be used.

\subsection{Multi-layer experiments}

The multi-layer experiments were carried out to facilitate the characterization of samples. For the characterization, a block of size $40 \times 20 \times 20 \mathrm{~mm}^{3}$ has been manufactured by TIG-HLM process, see Fig. 13a. The cladding parameters were: wire feed rate of $2000 \mathrm{~mm} / \mathrm{min}$, torch speed of $200 \mathrm{~mm} / \mathrm{min}$, current of $200 \mathrm{amps}$, standoff distance of $7 \mathrm{~mm}$, stepover $4 \mathrm{~mm}$ (calculated using Fig. 12d and Eq. 7). The layer thickness is kept to $1 \mathrm{~mm}$. Multi-layer experiments are further divided into three experiments explained in next sections.

\subsubsection{X-ray analysis}

For checking interlayer fusion quality of the build X-ray test has been done. The results are shown in Fig. 13 from which it can be observed that the multi-layer deposition by TIG cladding gives a uniform and flawless interlayer fusion.

A miniature block of size $10 \times 10 \times 10 \mathrm{~mm}^{3}$ has been cutout from the original block and tests have been performed to observe the hardness and microstructure in the following paragraphs.

\subsubsection{Hardness test}

Nano-indentation testing was carried out on the cross section of the miniature block. These tests were carried out at top and bottom layer across the stepover and along the 
Table 7 Detailed results of ANOVA calculation

\begin{tabular}{|c|c|c|c|c|c|}
\hline Process parameter & DOF & SS & MS & $F$ & $\%$ contribution \\
\hline \multicolumn{6}{|l|}{ (a) For bead width } \\
\hline Wire feed & 3 & 2.57 & 0.85 & 3.25 & 5.46 \\
\hline Torch speed & 3 & 20.09 & 6.69 & 25.38 & 42.63 \\
\hline Current & 3 & 17.24 & 5.74 & 21.77 & 36.57 \\
\hline Stand of distance & 3 & 6.42 & 2.14 & 8.12 & 13.64 \\
\hline Error & 3 & 0.79 & 0.26 & 1 & 1.68 \\
\hline Total & 15 & 47.13 & & & \\
\hline \multicolumn{6}{|l|}{ (b) For bead height } \\
\hline Wire feed & 3 & 20.23 & 6.74 & 22.70 & 37.20 \\
\hline Torch Speed & 3 & 6.41 & 2.13 & 7.20 & 11.80 \\
\hline Current & 3 & 9.53 & 3.17 & 10.69 & 17.52 \\
\hline Stand of distance & 3 & 17.30 & 5.76 & 19.41 & 31.82 \\
\hline Error & 3 & 0.89 & 0.29 & 1 & 1.63 \\
\hline Total & 15 & 54.37 & & & \\
\hline \multicolumn{6}{|c|}{ (c) For bead penetration } \\
\hline Wire feed & 3 & 66.92 & 22.30 & 3.02 & 55.14 \\
\hline Torch speed & 3 & 9.50 & 3.16 & 0.42 & 7.83 \\
\hline Current & 3 & 19.38 & 6.46 & 0.87 & 15.97 \\
\hline Stand of distance & 3 & 3.39 & 1.13 & 0.15 & 2.79 \\
\hline Error & 3 & 22.15 & 7.38 & 1 & 18.25 \\
\hline Total & 15 & 121.37 & & & \\
\hline
\end{tabular}

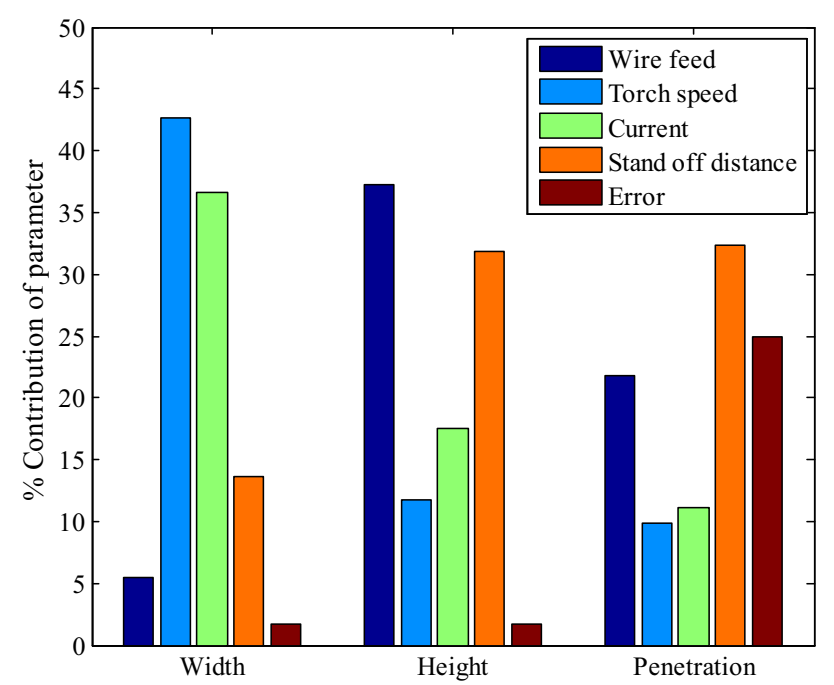

Fig. 9 Effect of factors on weld bead properties

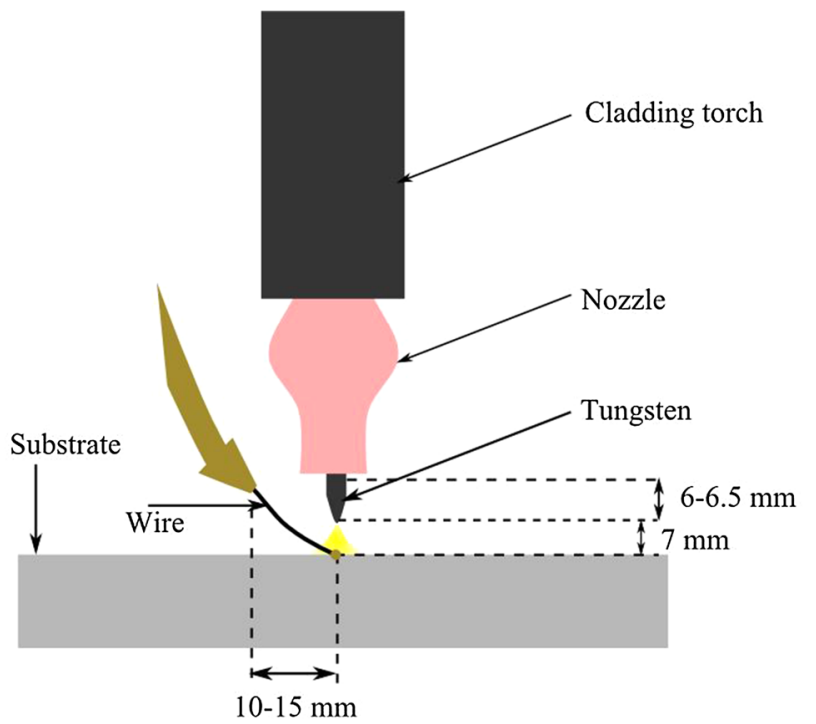

Fig. 11 Optimal position of nozzle and wire

sidewall (build direction). Figure 14 shows the location of the points on the miniature block. The results of the hardness test are shown in Table 8. The variation in hardness can be attributed to the number of thermal cycles a given layer undergoes. One can conclude from it that the hardness of the top layer is more than that of the bottom layer. This change in the microstructure is caused by the recrystallization of layers due to re-melting of previously deposited layers.

\subsubsection{Microstructure analysis}

Electron backscattered diffraction (EBSD) has been performed to understand the effect of thermal cycles on the microstructure of different layers. A single block of ten layers was built using optimal deposition parameters. EBSD mapping used a $300 \times 600$ point grid at $0.4-\mu \mathrm{m}$ steps. The grain size measurements were carried out on different layers (along the build structure) to gain a better understanding of the effect of process parameters on the microstructure gradient. The course and fine regions of the optical microscopy image of the microstructure were captured and average grain sizes were considered for top, bottom and intermediate layers. Figure 14 shows the
Fig. 10 Layer thickness with stepover increment

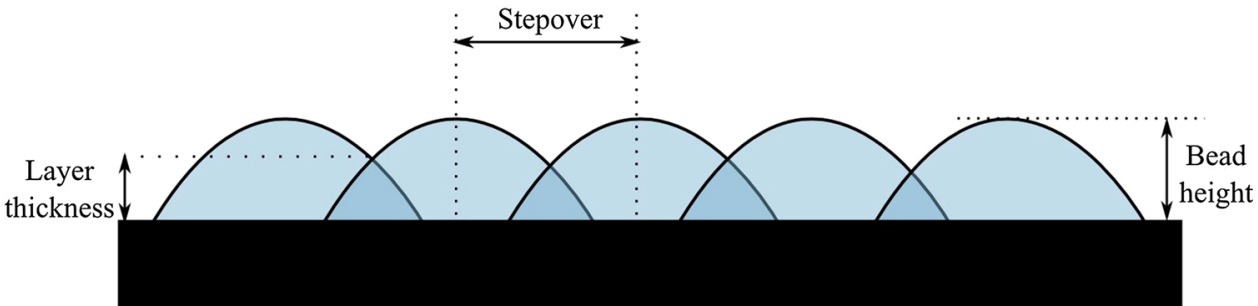


Fig. 12 Results of penetration, width and height for single bead for different wire feeds

(200 $\mathrm{mm} / \mathrm{min}$ torch speed and $7 \mathrm{~mm}$ stand off distance) a $1250 \mathrm{~mm} / \mathrm{min}$, b $1500 \mathrm{~mm} /$ $\mathrm{min}$, c $1750 \mathrm{~mm} / \mathrm{min}$, d $2000 \mathrm{~mm} / \mathrm{min}$, e $2250 \mathrm{~mm} /$ $\mathrm{min}, \mathbf{f} 2500 \mathrm{~mm} / \mathrm{min}$, g $2750 \mathrm{~mm} / \mathrm{min}$, h $3000 \mathrm{~mm} /$ $\min$

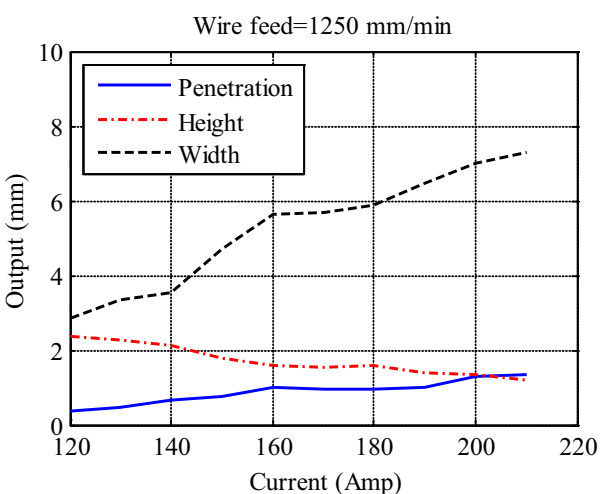

(a)

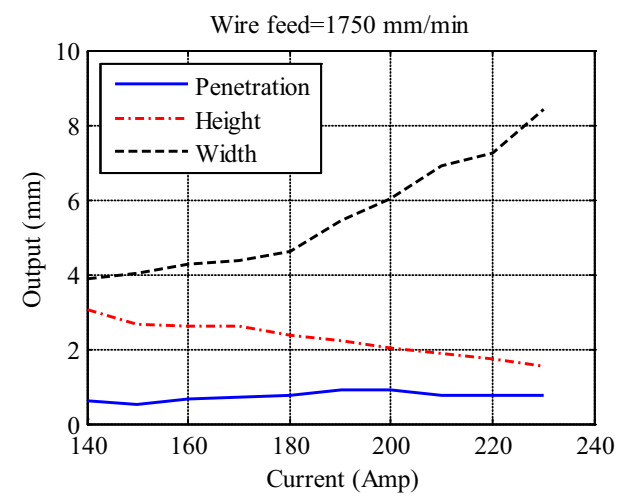

(c)

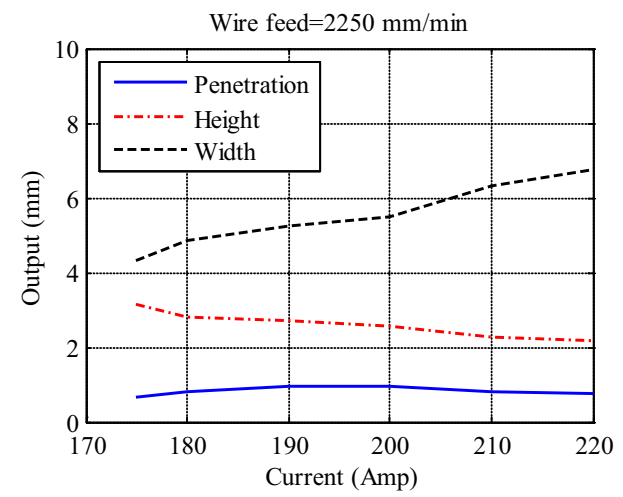

(e)

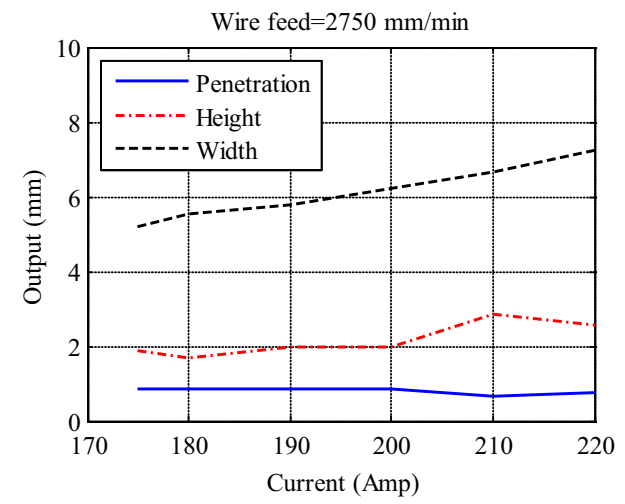

(g)

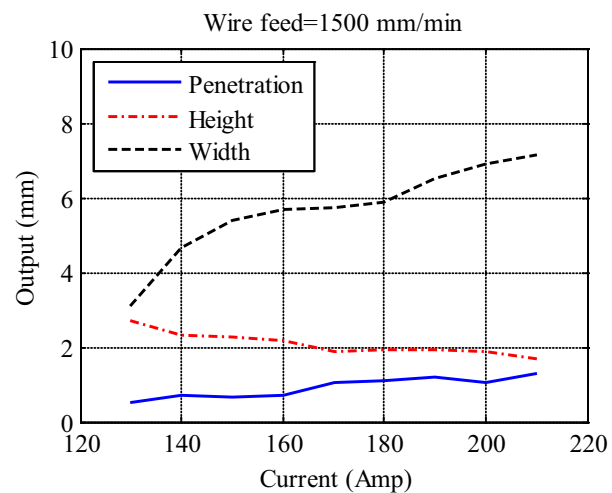

(b)

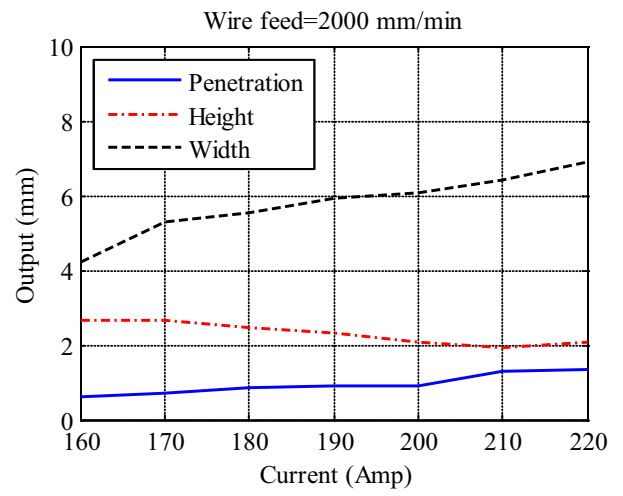

(d)

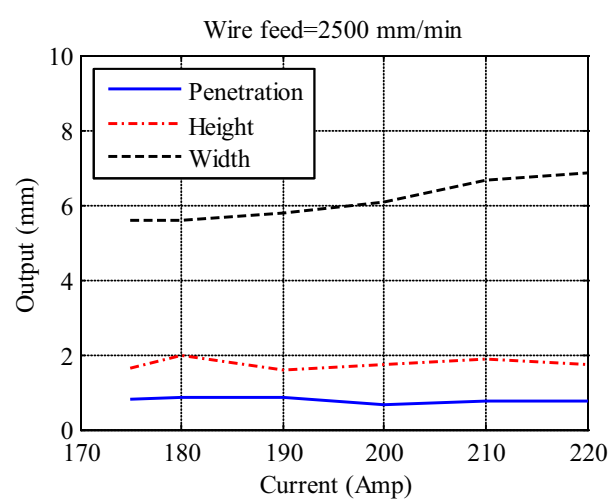

(f)

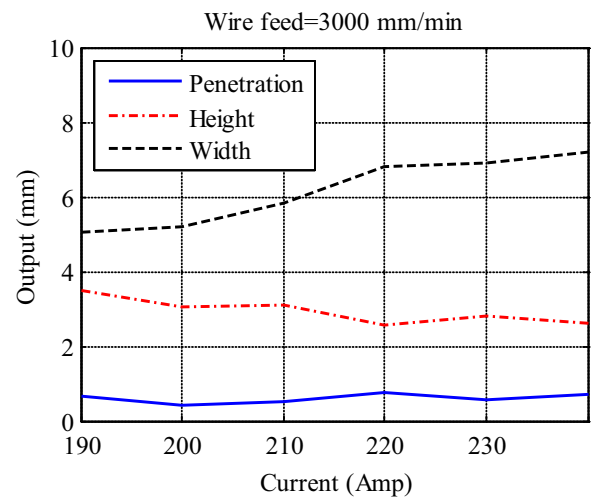

(h) 


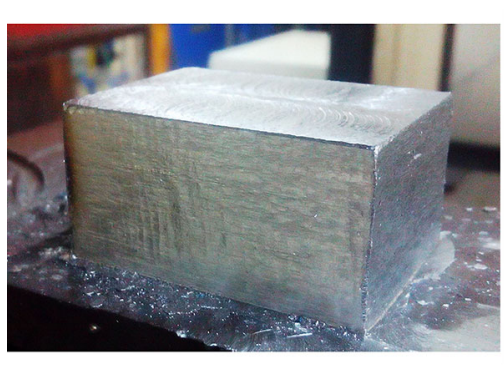

(a)

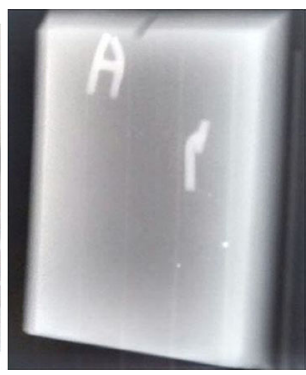

(b)
Fig. 13 a Deposited multi-layered block, b X-ray results of the block

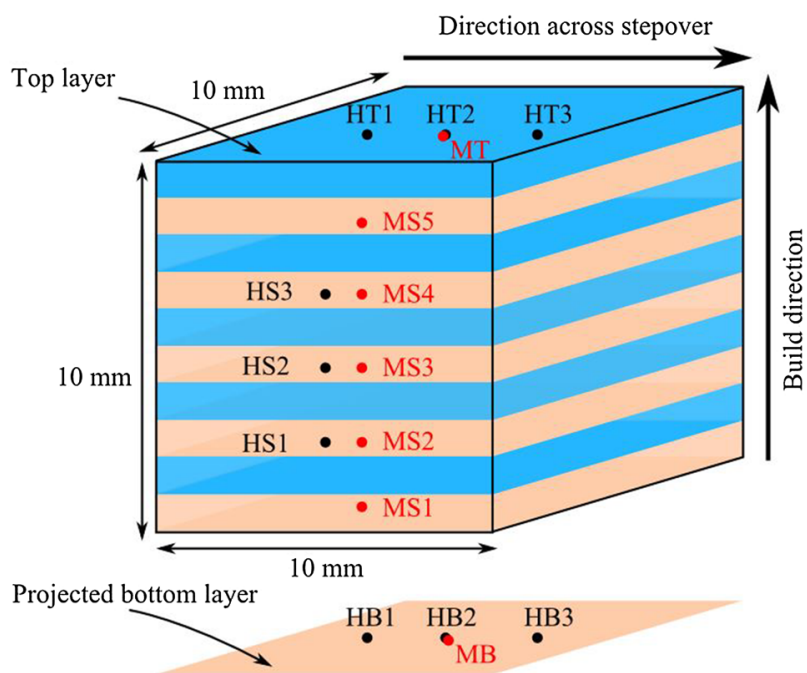

Fig. 14 Location of the test points on the miniature block

Table 8 Results of hardness test on the sample

\begin{tabular}{llll}
\hline $\begin{array}{l}\text { Layer } \\
\text { position }\end{array}$ & Location & $\begin{array}{l}\text { Hardness } \\
(\text { HRB })\end{array}$ & $\begin{array}{l}\text { Average hardness } \\
\text { (HRB) }\end{array}$ \\
\hline Top & HT1 & 88.96 & 90.90 \\
& HT2 & 90.16 & \\
Bottom & HT3 & 93.60 & \\
& HB1 & 82.31 & 82.54 \\
& HB2 & 83.21 & \\
Side wall & HB3 & 82.11 & \\
& HS1 & 82.13 & 84.29 \\
& HS2 & 84.25 & \\
& HS3 & 86.50 & \\
\hline
\end{tabular}

location of the points on the miniature block. Figure 15 shows the microstructure for different layers and Table 9 shows the average grain sizes.

It has been observed that the sample which has good structural integrity and phase for all layers is alpha iron. However, due to the difference in thermal cycle and

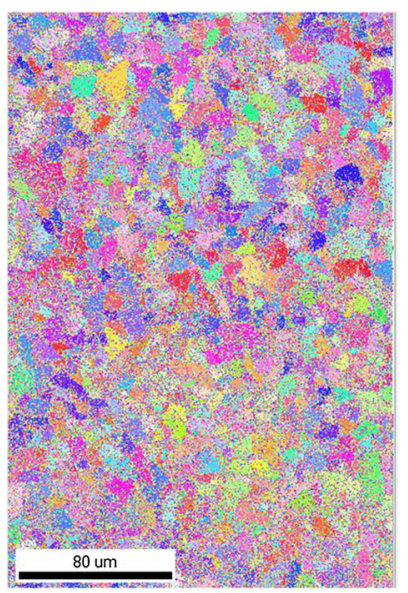

(a)

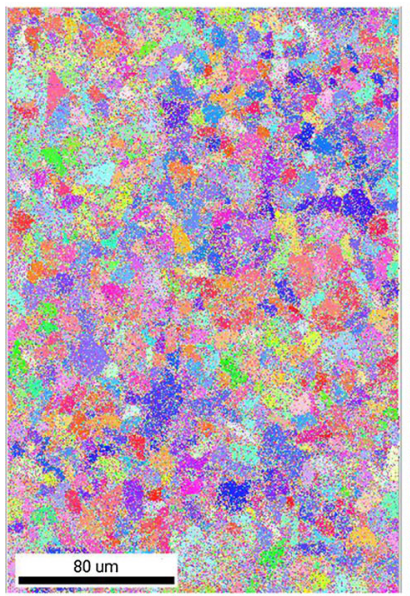

\section{(c)}

Fig. 15 a EBSD of top layer (grain size $4.39 \mu \mathrm{m}$ ), b microstructure of bottom layer (grain size $8.9 \mu \mathrm{m}$ ), $\mathbf{c}$ microstructure of middle layers (grain size 5.33 and $6.75 \mu \mathrm{m}$ )

Table 9 Grain size in different layers

\begin{tabular}{ll}
\hline Position & Grain size $($ diameter in $\mu \mathrm{m})$ \\
\hline Top & \\
MT & 4.39 \\
Side & \\
MS2 & 5.33 \\
MS3 & 6.12 \\
MS4 & 6.75 \\
MS5 & 8.12 \\
Bottom & \\
MB & 8.90 \\
\hline
\end{tabular}

cooling sequence of each layer, the microstructure showed a distinct variation along the layer thickness. EBSD maps show the fine microstructure at the top layer and coarse 
microstructure at bottom layers. But the variation is as small as it can be removed by in situ hammering process.

\section{Case study}

A cylindrical object of outer diameter $73 \mathrm{~mm}$, inner diameter $67 \mathrm{~mm}$ and height $50 \mathrm{~mm}$ has been manufactured using TIG-HLM. Figure 16a shows the CAD model of the component along with the other geometric parameters (layer thickness $=1 \mathrm{~mm}$ and machining allowance $=1 \mathrm{~mm}$ ). Figure $16 \mathrm{~b}$ shows the slicing of the object with $1 \mathrm{~mm}$ layer thickness. The wall thickness of the near-net shape of the object should be $5 \mathrm{~mm}$ (including $2 \mathrm{~mm}$ machining allowance). Hence, cladding toolpath is a circle of radius $35 \mathrm{~mm}$, see Fig. 17a. The cladding parameters are: wire feed rate $=2000 \mathrm{~mm} / \mathrm{min}$, torch speed $=200 \mathrm{~mm} / \mathrm{min}$, current $=180 \mathrm{Amps}$, and standoff distance $=7 \mathrm{~mm}$. The output parameters of single bead are (observed from Fig. 12d): bead width $\approx 5.5 \mathrm{~mm}$ and bead height $\approx 2 \mathrm{~mm}$. Figure $17 \mathrm{~b}$ shows the deposited first layer of the component. To maintain the constant layer thickness of $1 \mathrm{~mm}$ the deposited layer is face milled at a height of $1 \mathrm{~mm}$, see Fig. 17c. The deposition and face

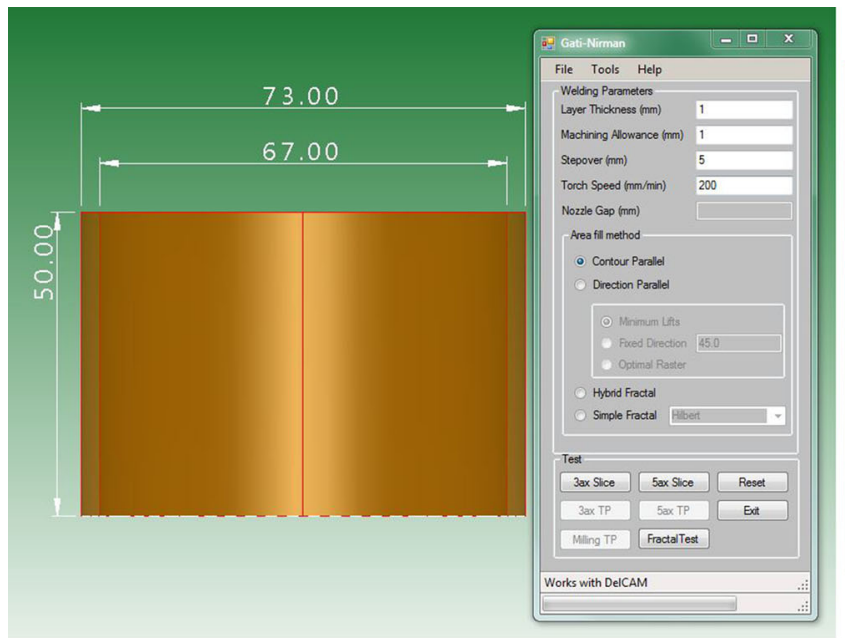

(a)

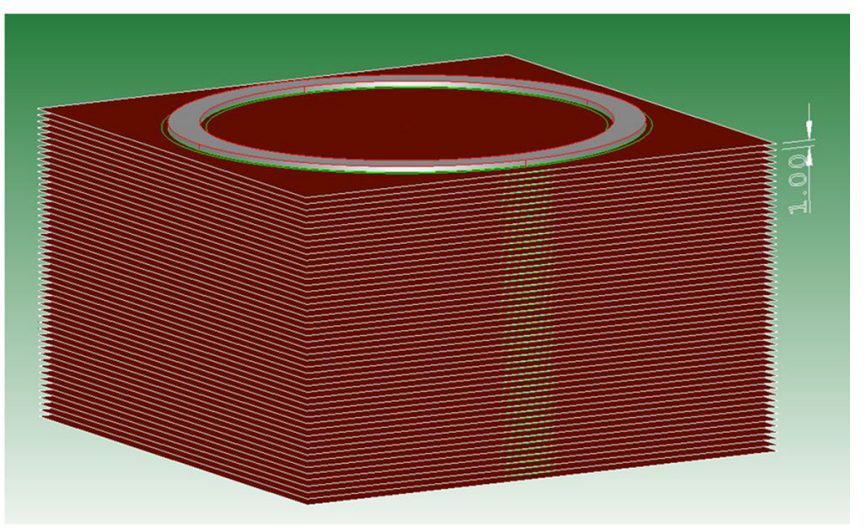

(b)

Fig. 16 a CAD model of the part to be manufactured, b slicing of the component

Fig. 17 a Toolpath of the first layer, $\mathbf{b}$ deposited bead in first layer, $\mathbf{c}$ first layer after face milling at $1 \mathrm{~mm}$

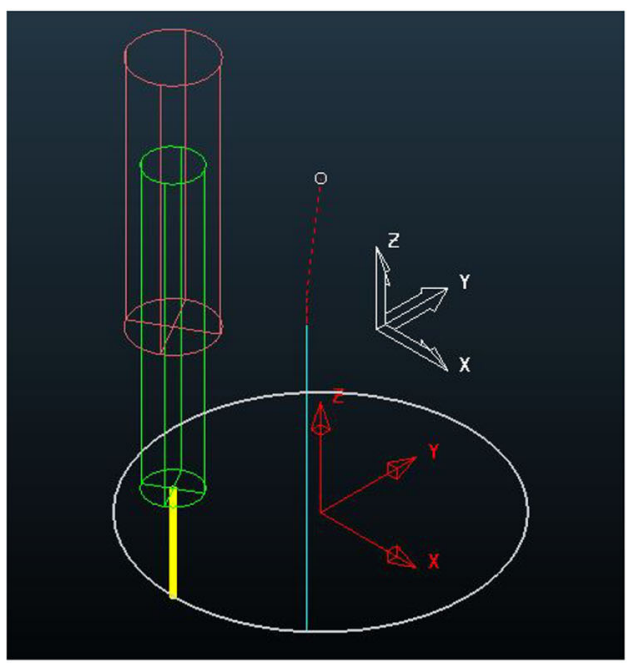

(a)

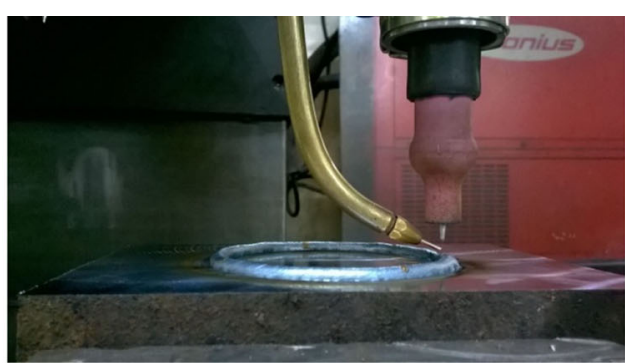

(b)

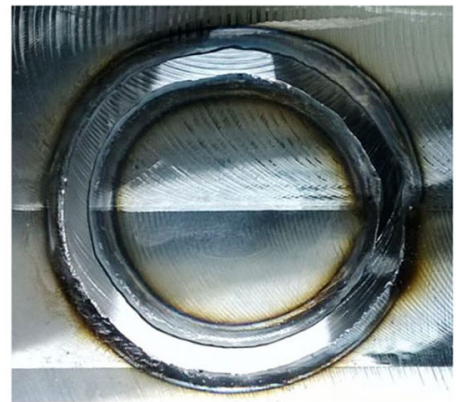

(c) 
Fig. 18 a Near-net shape of the component, b finished component after milling operation

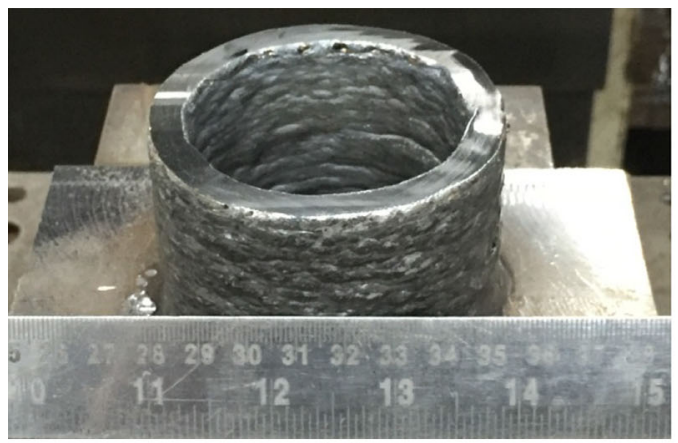

(a)

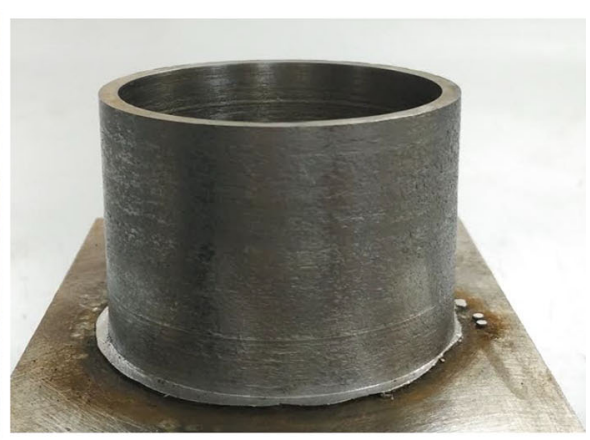

(b) milling are repeated for the next 50 layers to get the nearnet shape of the component. Figure 18a shows the near-net shape of the component. After milling operation on the same machine, the finished component is obtained as shown in Fig. 18b.

\section{Conclusion}

In this work, tungsten inert gas (TIG) cladding-based hybrid-layered manufacturing (HLM) process has been successfully stabilized on a CNC machine. To retrofit the cladding torch on the machine, a retractable pneumatic assembly has been manufactured to ensure that the torch does not interfere during the milling operation. Among all the parameters of TIG cladding process, the parameters which influence the near-net shape of the objects the most are identified and studied with three types of experiments: single-bead experiments, multi-bead experiments and multi-layer experiments. Taguchi and ANOVA have been used for the design of single-bead experiments and it has been found that the percentage contribution of torch speed, wire feed and standoff distance is the highest on bead width, height and penetration, respectively. For multi-bead experiments the width and height of bead has been recorded for varying process parameters so that the optimal pitch can be predicted for any given set of parameters. In multi-layer experiments, X-ray, hardness and microstructure tests have been conducted. The X-ray test shows uniform and flawless fusion between the consecutive layers. The hardness of the component is found to be increasing from bottom to top layer while the grain sizes are decreasing.

TIG cladding-based HLM can produce a good quality near-net shape of the desired component. The near-net shape can then further be finished by machining operation to give final dimensional accuracy to the component so that it can be used as a fully functional product. The cylindrical object manufactured in the case study proves the capability of this process.

\section{References}

1. Kovacevic R, Beardsley H (1998) Process control of 3D welding as a droplet-based rapid prototyping technique. In: Proceedings of solid freeform symposium, pp 55-64

2. Jandric Z, Labudovic M, Kovacevic R (2004) Effect of heat sink on microstructure of three-dimensional parts built by weldingbased deposition. Int J Mach Tools Manuf 44(7-8):785-796

3. Wang H, Jiang W, Ouyang J, Kovacevic R (2004) Rapid prototyping of 4043 Al-alloy parts by VP-GTAW. J Mater Process Technol 148(1):93-102

4. Wu Y, Kovacevic R (2002) Mechanically assisted droplet transfer process in gas metal arc welding. Proc Inst Mech Eng Part B: J Eng Manuf 216(4):555-564

5. Katou M, Oh J, Miyamoto Y, Matsuura K, Kudoh M (2007) Freeform fabrication of titanium metal and intermetallic alloys by three-dimensional micro welding. Mater Des 28(7):2093-2098

6. Horii T, Kirihara S, Miyamoto Y (2008) Freeform fabrication of Ti$\mathrm{Al}$ alloys by 3D micro-welding. Intermetallics 16(11-12):1245-1249

7. Horii T, Kirihara S, Miyamoto Y (2009) Freeform fabrication of super alloy objects by 3D micro welding. Mater Des 30(4):1093-1097

8. Merz R, Prinz F, Ramaswami K, Terk M, Weiss L (1994) Shape deposition manufacturing. In: 25th proceedings of solid freeform symposium Austin, pp 1-8

9. Weiss LE et al (1997) Shape deposition manufacturing of heterogeneous structures. J Manuf Syst 16(4):239-248

10. Martina F, Mehnen J, Williams SW, Colegrove P, Wang F (2012) Investigation of the benefits of plasma deposition for the additive layer manufacture of Ti-6Al-4V. J Mater Process Technol 212(6):1377-1386

11. Williams SW, Martina F, Addison C, Ding J, Pardal G, Colegrove $\mathrm{P}(2015)$ Wire + arc additive manufacturing. Mater Sci Technol 23:73-80

12. Xiong X, Zhang H, Wang G (2009) Metal direct prototyping by using hybrid plasma deposition and milling. J Mater Process Technol 209(1):124-130

13. Jhavar S, Jain NK, Paul CP (2014) Development of micro-plasma transferred arc wire deposition process for additive layer manufacturing applications. J Mater Process Technol 214(5):1102-1110

14. Juang SC, Tarng YS (2002) Process parameter selection for optimizing the weld pool geometry in the tungsten inert gas welding of stainless steel. J Mater Process Technol 122:33-37

15. Karunakaran KP, Suryakumar S, Pushpa V, Akula S (2009) Retrofitment of a CNC machine for hybrid layered manufacturing. Int J Adv Manuf Technol 45:690-703

16. Suryakumar S, Karunakaran KP, Bernard A, Chandrasekhar U, Raghavender N, Sharma D (2011) Weld bead modeling and process optimization in hybrid layered manufacturing. Comput Aided Des 43(4):331-344 